\title{
Nitrogen Contributions from Peanut Residues to Subsequent Crops ${ }^{1}$
}

\author{
Arun Jani and Michael J. Mulvaney ${ }^{2}$
}

\section{Introduction}

Cooperative Extension Services throughout the Southeast recommend that farmers reduce nitrogen $(\mathrm{N})$ fertilization to crops planted after peanut (Arachis hypogaea $\mathrm{L}$.). The $\mathrm{N}$ fertilizer replacement value of peanut residues is termed a "peanut $\mathrm{N}$ credit" and may result in lower production costs due to reduced fertilizer expenditures. However, field experiments conducted throughout the region have shown that fall- and spring-sown crops planted after peanut generally do not perform any better than when planted after other crops or when peanut hay is removed (Balkcom et al. 2007; Jordan et al. 2008; Meso et al. 2007). These experiments suggest that if there is a peanut $\mathrm{N}$ credit, it is too small to affect the performance of subsequent crops. It may be that field observations of peanut $\mathrm{N}$ credits are due to mulching effects or crop rotational benefits, but the impact of these factors has not been thoroughly investigated in the Southeast. While peanut residues should not be used as a substitute for $\mathrm{N}$ fertilization, retaining peanut residues on the soil surface may protect soil from erosion, enhance water retention and soil organic matter, and improve overall soil quality.

\section{Peanut Nitrogen Credits}

Peanut is one of the most economically important row crops in Florida, with approximately 158,000 ac under cultivation and an estimated annual production value of
$\$ 120$ million (FDACS 2017). In addition to peanut's value as a cash crop, peanut residues contain large amounts of $\mathrm{N}$ from biological $\mathrm{N}$ fixation. During this process, soil bacteria, collectively called rhizobia, penetrate peanut roots and supply the plant with $\mathrm{N}$ in exchange for carbon. As peanut residues decompose after harvest, $\mathrm{N}$ is released and made available to subsequent crops.

Throughout the peanut-growing region of the United States, Cooperative Extension Services recommend N credits to crops planted after peanut. From Virginia to Oklahoma, including Florida, Alabama, and Georgia, Extension Services recommend reducing $\mathrm{N}$ fertilization to subsequent fall- and spring-sown crops by $10-60 \mathrm{lb} \mathrm{N} / \mathrm{ac}$ (Buntin et al. 2007; Caddel et al. 2006; Harris 2013; Maguire and Heckendorn 2011; Mitchell and Phillips 2010; Wright, Marois, and Sprenkel 2011). Peanut N credits should reduce the $\mathrm{N}$ fertilizer requirements needed to meet yield goals of subsequent crops. If all the Florida peanut acreage provided an average of $30 \mathrm{lb} \mathrm{N} / \mathrm{ac}$ credit to a subsequent crop, that would equate to a savings of 4.74 million lb of mineral N/ year in Florida alone, or 10.3 million $\mathrm{lb}$ of urea/year worth over \$2 million.

There is a lack of scientific evidence to support peanut $\mathrm{N}$ credit recommendations in the region (Balkcom et al. 2007; Jordan et al. 2008; Meso et al. 2007). Unanswered questions regarding peanut $\mathrm{N}$ credits include:

1. This document is SS-AGR-432, one of a series of the Agronomy Department, UF/IFAS Extension. Original publication date April 2019. Visit the EDIS website at https://edis.ifas.ufl.edu for the currently supported version of this publication.

2. Arun Jani, PhD candidate; and Michael J. Mulvaney, assistant professor, Agronomy Department; UF/IFAS West Florida Research and Education Center, Jay, FL 32565.

The Institute of Food and Agricultural Sciences (IFAS) is an Equal Opportunity Institution authorized to provide research, educational information and other services only to individuals and institutions that function with non-discrimination with respect to race, creed, color, religion, age, disability, sex, sexual orientation, marital status, national origin, political opinions or affiliations. For more information on obtaining other UF/IFAS Extension publications, contact your county's UF/IFAS Extension office. 
- To what crop should the N credit be applied? Should it be applied to a fall-sown crop or a spring-sown crop? Does it matter?

- Should the $\mathrm{N}$ credit be applied to at-plant fertilizer applications or topdress applications?

- Should the N credit differ based on soil texture and climate (i.e., environment)?

- Is there still an $\mathrm{N}$ credit if peanut residues are removed from the field?

- Does the $\mathrm{N}$ credit differ if residues remain in windrows instead of being distributed using spreaders? Does the amount of residue change the $\mathrm{N}$ credit?

- Do tillage and the timing of incorporation affect the $\mathrm{N}$ credit?

This document provides an overview of current, sciencebased information on peanut $\mathrm{N}$ credits to subsequent crops for Extension agents and specialists, regulatory officials, consultants, agricultural professionals, and farmers in the Southeast. It also discusses agronomic management and environmental factors that may contribute to the absence of peanut $\mathrm{N}$ credits in the region.

\section{Nitrogen Release from Peanut Residues}

The amount of $\mathrm{N}$ accumulated by peanut residues is determined by multiplying the percentage of $\mathrm{N}$ in residues by the amount of residues produced per acre. By tracking the amount of $\mathrm{N}$ released from peanut residues over time, it is possible to estimate how much residue-derived $\mathrm{N}$ is potentially available for subsequent crops.

The litterbag method is one common method to track $\mathrm{N}$ release from peanut residues. In this method, permeable nylon bags are filled with peanut residues at typical loading rates $(3,500-4,000 \mathrm{lb} / \mathrm{ac})$, placed in the field, and collected periodically to determine the amount of $\mathrm{N}$ remaining in residues over time. Subtracting the amount of $\mathrm{N}$ remaining at any time point from the amount of $\mathrm{N}$ remaining at an earlier time point provides an estimate of $\mathrm{N}$ released from residues during that period. For example, Figure 1 presents a general schematic diagram that indicates peanut residues would release $14 \mathrm{lb} \mathrm{N} / \mathrm{ac}$ during a hypothetical wheat crop. This quantity may change depending on residue management practices, which are discussed later in this document.

Note that litterbags exclude most insects and small animals that would otherwise consume or transport residues (Bradford et al. 2002; Tian et al. 1992; Vreeken-Buijs and
Brussaard 1996). Additionally, litterbags serve as a barrier between soil and residues, which slows down decomposition. Therefore, $\mathrm{N}$ release from peanut residues would likely be faster under natural conditions when litterbags are not used.

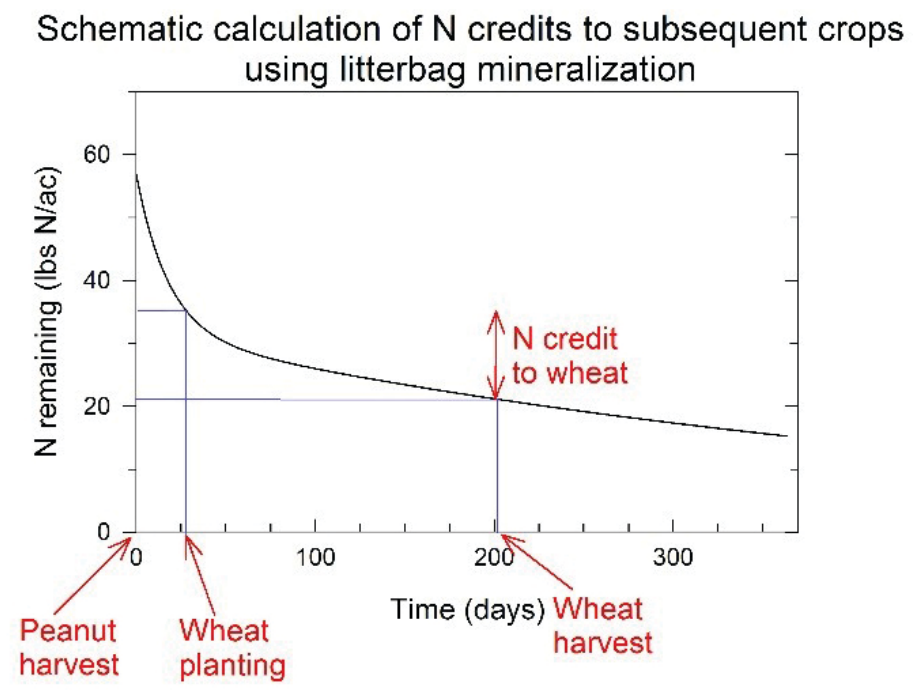

Figure 1. Schematic calculation of $\mathrm{N}$ credits using litterbags. The difference between the amount of $\mathrm{N}$ remaining at two different time points is the amount released during that time.

Credits: Michael J. Mulvaney, UF/IFAS

\section{Crop Performance following Peanut}

Results from field experiments conducted throughout the Southeast do not provide evidence for peanut $\mathrm{N}$ credits. Field studies conducted in Alabama showed that biomass accumulation by a fall-sown rye (Secale cereale L.) cover crop was not affected by the presence of peanut residues in the field (Balkcom et al. 2007). Similar results were observed in Florida where biomass accumulation by an oat (Avena sativa L.) cover crop was not consistently higher following peanut compared to following cotton (Gossypium hirsutum L.) (Zhao et al. 2010). Winter cereals like rye and oat are normally planted about one month after harvesting peanut and are known for their deep root systems and ability to scavenge for nutrients. The unresponsiveness of winter cereals to peanut makes it unsurprising that subsequent spring-sown crops planted several months after harvesting peanut would also be unresponsive. For example, researchers in Alabama showed that cotton yields did not increase when peanut residues were present (Meso et al. 2007). In North Carolina, researchers reported that neither corn (Zea mays L.) nor cotton yields were affected by rotations with or without peanut under both conventional and conservation tillage (Jordan et al. 2008). 
Agronomic management and environmental factors may explain the absence of peanut $\mathrm{N}$ credits in the region. Management factors that affect $\mathrm{N}$ release and availability from peanut residues include tillage, planting time of subsequent crops, and peanut residue loading rate and distribution. Environmental factors, such as temperature, rainfall patterns, and soil nutrient holding capacity, are also important. These management and environmental factors are described in greater detail below.

\section{Tillage and Nitrogen Release}

Soil tillage practices affect peanut residue decomposition and $\mathrm{N}$ release rates. Incorporating residues with conventional tillage increases microbial access to residues compared to leaving residues on the soil surface. With greater access, soil microorganisms rapidly decompose incorporated residues and release $\mathrm{N}$ during the process.

Nitrogen is generally released most rapidly from peanut residues in the weeks immediately following harvest. Release rates will be especially rapid if rainfall is abundant and temperatures are warm, as is often the case during fall in the Southeast. Litterbag experiments in Alabama showed that 48 and $30 \%$ of $\mathrm{N}$ from incorporated and surface residues, respectively, was released within 30 days after harvest (Mulvaney et al. 2017). A typical peanut residue load of 3,000 lb/ac contains approximately $60 \mathrm{lb} \mathrm{N} / \mathrm{ac}$. If a winter cereal is planted on November 1 (approximately 30 days after peanut harvest), then 31 and $42 \mathrm{lb} \mathrm{N} /$ ac would remain from incorporated and surface peanut residues, respectively, at the time of planting, but only a fraction of that would be released during the season. The amount of $\mathrm{N}$ potentially available from peanut residues to spring-sown crops is smaller. Experiments in Florida and Alabama showed that only 2-8 and 2-16 lb N/ac from fall-incorporated and surface peanut residues, respectively, would be released during a cotton crop planted the following spring (Table 1) (Jani et al. 2019; Mulvaney et al. 2017).

Keep in mind that only a portion of $\mathrm{N}$ released from peanut residues during a subsequent crop is actually used by that crop. There are several pathways by which peanut residue $\mathrm{N}$ is made unavailable to roots. Nitrogen released from peanut residues can be leached out of the crop root zone with rainfall, a major source of $\mathrm{N}$ loss in sandy soils of Florida. In addition, if residues are left on the soil surface under conservation tillage, a portion of $\mathrm{N}$ may volatilize. Soil microorganisms also compete with roots for available $\mathrm{N}$, representing another pathway by which $\mathrm{N}$ derived from residues becomes unavailable. Considering the different pathways by which $\mathrm{N}$ becomes unavailable to plants, it is not surprising that $\mathrm{N}$ use efficiency (NUE) by cereals and cotton is estimated to be only 33-44\% (Li et al. 2016; Raun and Johnson 1999). The amount of peanut residue $\mathrm{N}$ actually used by winter cereals or spring-sown crops such as cotton is likely insufficient to increase yields.

Table 1. Estimates of $\mathrm{N}$ released from different quantities of incorporated and surface peanut residues during wheat and cotton crops (Jani et al. 2018; Mulvaney et al. 2017).

\begin{tabular}{|c|c|c|}
\hline $\begin{array}{c}\text { Residue Load (Ib/ } \\
\text { ac) }\end{array}$ & \multicolumn{2}{|c|}{$\begin{array}{c}\text { Nitrogen Released during Season (lb N/ } \\
\text { ac) }\end{array}$} \\
\cline { 2 - 3 } & Wheat & Cotton \\
\hline & Incorporated Residue \\
\hline 1,000 & 3 & 2 \\
\hline 2,000 & 4 & 3 \\
\hline 3,000 & 18 & 5 \\
\hline 4,000 & 30 & 8 \\
\hline 6,000 & 31 & 4 \\
\hline & Surface Residue & 2 \\
\hline 1,000 & 5 & 4 \\
\hline 2,000 & 11 & 3 \\
\hline 3,000 & 29 & 10 \\
\hline 4,000 & 21 & 16 \\
\hline 6,000 & 36 & \\
\hline
\end{tabular}

\section{Peanut Residue Distribution and Nitrogen Release}

The amount of peanut residue $\mathrm{N}$ potentially available for subsequent crops also depends on the quantity of residue left in the field following peanut harvest. Peanut biomass accumulation can vary substantially in the Southeast, ranging from 2,900 to 4,460 lb/ac, which amounts to 41 and $71 \mathrm{lb} \mathrm{N} / \mathrm{ac}$, respectively (Jani et al. 2017; Meso et al. 2007). As stated earlier, not all of this $\mathrm{N}$ will be available for crops planted after peanut.

Peanut harvest practices create an uneven distribution of residues in the field. Placement of peanut in windrows after digging concentrates residues over a relatively small area. Peanut pickers may not be equipped with residue spreaders. If spreaders are not used, residues will remain in windrows (Figure 2), resulting in large spatial variability of potentially available $\mathrm{N}$ for subsequent crops. Farmers often observe a "windrow effect" whereby crops planted after peanut perform best where peanut was windrowed (Figures 3 and 4). Researchers in Florida explored the effects that windrowing may have on spatial variation of residue $\mathrm{N}$ in a litterbag experiment. Peanut residues were applied at rates that reflected the postharvest residue distribution gradient when residue spreaders are not used $(1,000,2,000,4,000$, and $6,000 \mathrm{lb} / \mathrm{ac})$. Higher loading rates $(4,000$ and $6,000 \mathrm{lb} /$ 
ac) represented areas on or near former windrows, while smaller loading rates $(1,000$ and $2,000 \mathrm{lb} / \mathrm{ac})$ represented areas farther away from windrows.

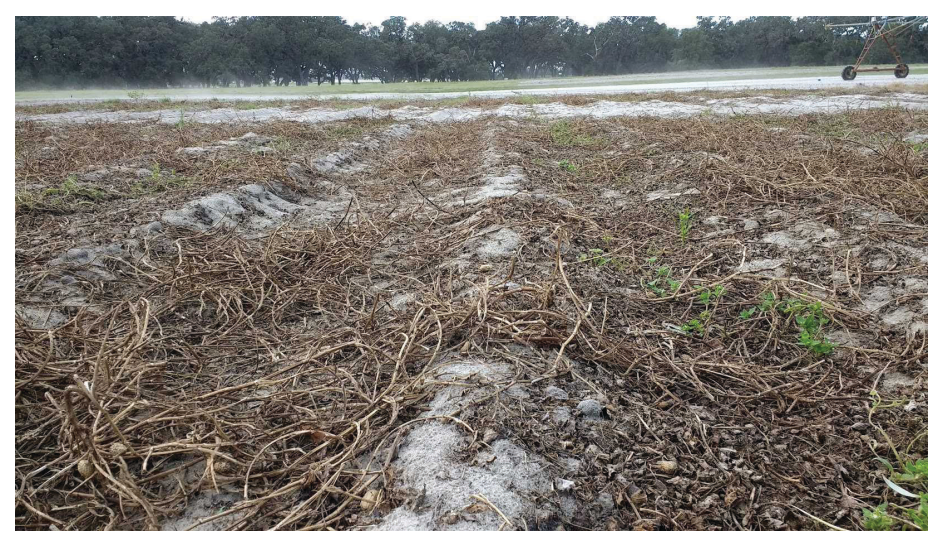

Figure 2. Peanut residues are concentrated in former windrows when residue spreaders are not used at harvest.

Credits: Arun Jani, UF/IFAS
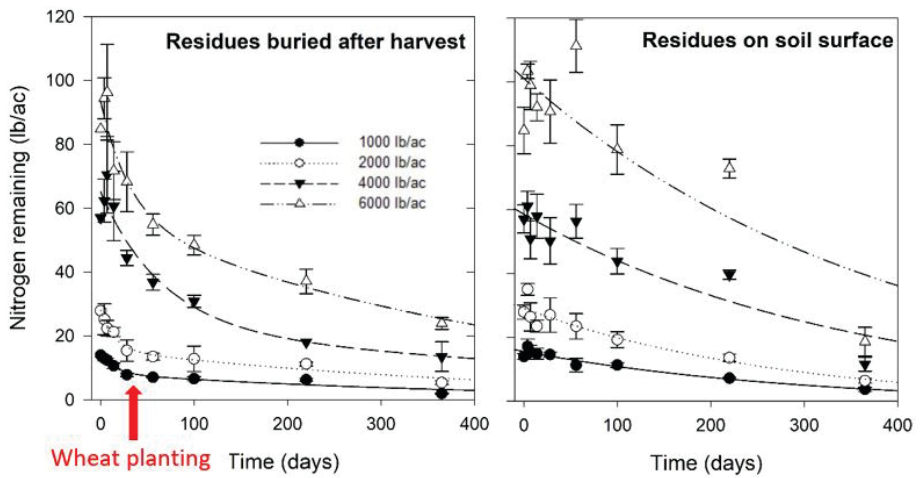

Figure 3. The amount of $\mathrm{N}$ remaining from peanut residues over time at four residue loading rates $(1,000,2,000,4,000$, and 6,000 lb/ac) and two placements (buried vs. on surface) in Citra, Florida. A theoretical wheat crop would be planted at day 30 (Jani et al. 2018).

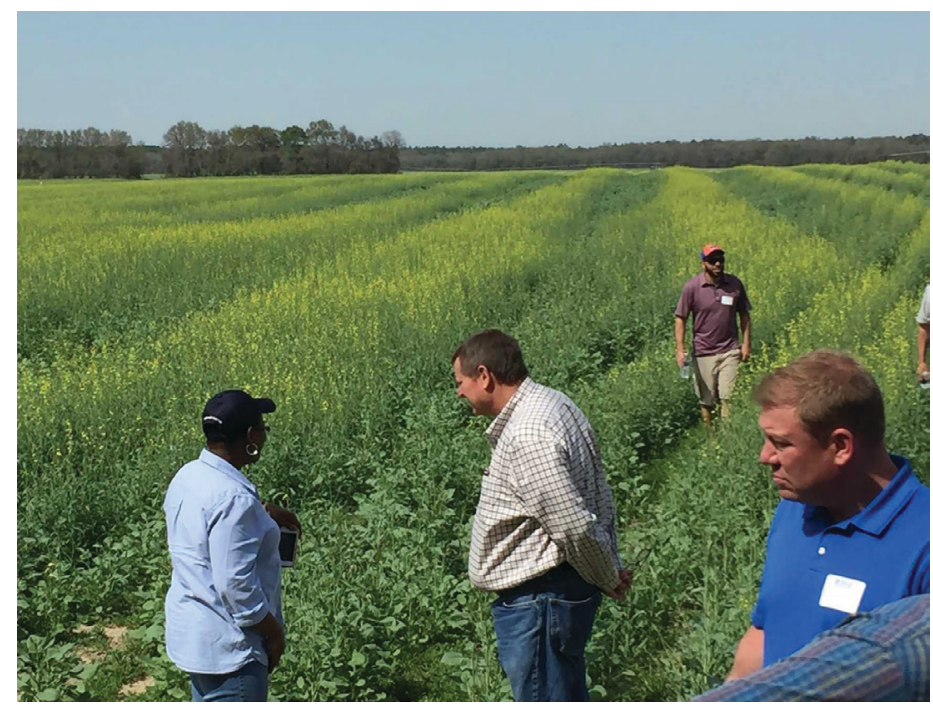

Figure 4. Carinata (Brassica carinata) crop following peanut. Strips of blooming carinata can be seen on former peanut windrows.

Credits: Michael J. Mulvaney, UF/IFAS
Regardless of tillage practice, residues loaded at higher rates (near or on former windrows) supplied substantially more $\mathrm{N}$ than smaller residue loading rates (Figure 3). However, at higher loading rates, more $\mathrm{N}$ was released rapidly and was subject to environmental losses or consumption by soil microorganisms. As previously mentioned, $\mathrm{N}$ release from peanut residues is fastest after harvest, which results in a lack of synchrony between residue $\mathrm{N}$ supply and demand by subsequent crops. In the case of a spring-sown crop, most $\mathrm{N}$ from peanut residues, even at high loading rates, would likely have already left the rooting zone by spring planting. Therefore, even in areas of the field where peanut residue $\mathrm{N}$ supply is high, such as in former windrows, the amount of $\mathrm{N}$ available to a subsequent crop is still relatively low under environmental conditions in Florida. The commonly observed "windrow effect" is most likely due to factors unrelated to $\mathrm{N}$, such as greater soil organic matter and moisture retention, lower erosion, and cooler soil temperatures.

\section{Conclusion}

There is not enough evidence to support current peanut $\mathrm{N}$ credit recommendations in the Southeast. Nitrogen is released rapidly from peanut residues, and it moves quickly through light-textured soils found in this region. Only a relatively small amount of $\mathrm{N}$ from peanut residues is available when subsequent crops need it.

\section{References}

Anuar, A. R., Z. H. Shamsuddin, and O. Yaacob. 1995. "Contribution of legume-N by nodulated groundnut for growth of maize on an acid soil." Soil Biol. Biochem. 27: 595-601.

Balkcom, K. S., C. W. Wood, J. F. Adams, and B. Meso. 2007. "Suitability of peanut residue as a nitrogen source for a rye cover crop." Sci. Agric. 64: 181-186. doi:10.1590/ S0103-90162007000200012

Bradford, M. A., G. M. Tordoff, T. Eggers, T. H. Jones, and J. E. Newington. 2002. "Microbiota, fauna, and mesh size interactions in litter decomposition." Oikos 99: 317-323. doi:10.1034/j.1600-0706.2002.990212.x.

Buntin, G. D., T. L. Grey, G. H. Harris, D. Phillips, E. P. Prostko, P. Raymer, N. B. Smith, P. E. Sumner, and J. Woodruff. 2007. "Canola production in Georgia." UGA Ext. B. 1331. Athens, GA: University of Georgia Cooperative Extension. 
Caddel, J., D. Redfearn, H. Zhang, J. Edwards, and S. Deng. 2006. "Forage legumes and nitrogen production." Oklahoma State University Extension Facts, No. 2590: 6.

Cherr, C. M., J. M. S. Scholberg, and R. McSorley. 2006. "Green manure as nitrogen source for sweet corn in a warm-temperate environment." Agron. J. 98: 1173-1180. doi:10.2134/agronj2005.0036

Florida Department of Agriculture and Consumer Services (FDACS). 2017. "Florida Agriculture by the Numbers." Accessed on April 5, 2019. https://www.nass.usda.gov/ Statistics_by_State/Florida/Publications/Annual_Statistical_Bulletin/index.php

Harris, G. 2013. "Wheat Fertilization and Timing." In Southern Small Grains Resource Management Handbook, edited by UGA. 19-20. Athens, GA: University of Georgia.

Jani, A. D., M. J. Mulvaney, J. E. Erickson, R. G. Leon, C. W. Wood, and D. L. Rowland. 2017. "Evaluation of peanut residue nitrogen contributions to wheat in a conservation tillage cropping system." In ASA-CSSA-SSSA Annual Meeting Abstracts. ASA-CSSA-SSSA Annual Meeting. Tampa, FL.

Jani, A. D., M. J. Mulvaney, H. A. Enloe, J. E. Erickson, R. G. Leon, D. L. Rowland, and C. W. Wood. 2019. "Peanut residue distribution gradients and tillage practices determine patterns of nitrogen mineralization." Nut. Cycl. Agroecosyst. 113: 63-76.

Jordan, D. L., J. S. Barnes, T. Corbett, C. R. Bogle, P. D. Johnson, B. B. Shew, S. R. Koenning, W. Ye, and R. L. Brandenburg. 2008. "Crop response to rotation and tillage in peanut-based cropping systems.” Agron. J. 100: 1580-1586. doi:10.2134/agronj2008.0075

Li, Q., N. Liao, N. Zhang, G. Zhou, W. Zhang, X. Wei, J. Ye, and Z. Hou. 2016. "Effects of cotton (Gossypium hirsutum L.) straw and its biochar application on $\mathrm{NH}_{3}$ volatilization and $\mathrm{N}$ use efficiency in a drip-irrigated cotton field." Soil Sci. Plant Nutr. 62: 534-544.

Maguire, R. O., and S. E. Heckendorn. 2011. Soil test recommendation for Virginia. Blacksburg, VA: Virginia Tech.

Meso, B., K. S. Balkcom, C. W. Wood, and J. F. Adams. 2007. "Nitrogen contribution of peanut residue to cotton in a conservation tillage system." J. Plant Nutr. 30: 1153-1165. doi:10.1080/01904160701394618
Mitchell, C. C., and S. Phillips. 2010. "Nitrogen recommendations." In Research-Based Soil Testing and Recommendations for Cotton on Coastal Plain Soils, edited by C. C. Mitchell. Auburn, AL: Alabama Agricultural Experiment Station.

Mulvaney, M. J., K. S. Balkcom, C. W. Wood, and D. Jordan. 2017. "Peanut residue carbon and nitrogen mineralization under simulated conventional and conservation tillage." Agron. J. 109: 696-705.

Raun, W. R., and G. V. Johnson. 1999. "Improving nitrogen use efficiency for cereal production.” Agron. J. 91: 357-363.

Sharma, A. R., and U. K. Behera. 2009. "Recycling of legume residues for nitrogen economy and higher productivity in maize (Zea mays)-wheat (Triticum aestivum) cropping system." Nutr. Cycl. Agroecosyst. 83: 197-210.

Tian, G., B. T. Kang, and L. Brussaard. 1992. "Biological effects of plant residues with contrasting chemical compositions under humid tropical conditions-Decomposition and nutrient release." Soil Biol. Biochem. 24: 1051-1060. http://dx.doi.org/10.1016/0038-0717(92)90035-V

Vreeken-Buijs, M. J., and L. Brussaard. 1996. "Soil mesofauna dynamics, wheat residue decomposition and nitrogen mineralization in buried litterbags." Biol. Fertil. Soils 23: 374-381. doi:10.1007/BF00335910.

Williams, J. D., C. R. Crozier, J. G. White, R. W. Heiniger, R. P. Sripada, and D. A. Crouse. 2007. "Illinois soil nitrogen test predicts southeastern U.S. corn economic optimum nitrogen rates." Soil Sci. Soc. Am. J. 71: 735-744.

Wright, D., J. Marois, and R. Sprenkel. 2011. Production of Ultra-Narrow-Row Cotton. SS-AGR-83. Gainesville: University of Florida Institute of Food and Agricultural Sciences. http://edis.ifas.ufl.edu/aa267

Zhao, D., D. L. Wright, J. J. Marois, C. L. Mackowiak, and M. Brennan. 2010. "Improved growth and nutrient status of an oat cover crop in sod-based versus conventional peanut-cotton rotations." Agron. Sustain. Dev. 30: 497-504. doi:10.1051/agro/2009045 